\title{
FENOMENA SPASIAL PADA FLY-OVER URIP SUMOHARJO KM.4
}

\author{
Muhammad Ajwad Muzdar *1 \\ Jurusan Teknik Arsitektur UIN Alauddin Makassar \\ e-mail: *1ajwad61@gmail.com
}

\begin{abstract}
Abstrak_ Fly-Over Urip Sumoharjo KM.4 Makassar merupakan jalan layang yang dibangun oleh Pemerintah Kota Makassar guna untuk memecah kemacetan yang sering terjadi malah menambah kemacetan di waktu-waktu tertentu karena adanya aktivitas lain yang dilakukan oleh masyarakat dan menjadi masalah spasial pada fly-over. Penelitian ini bertujuan mengungkapkan bentuk-bentuk aktivitas yang dilakukan oleh aktor dan kekuatan yang membentuk aktivitas. Lokasi penelitian yaitu di Fly-Over Urip Sumoharjo KM.4 Makassar. Metode penelitian dilakukan dengan metode kualitatif. Pengumpulan data dilakukan dengan wawancara, kuesioner, observasi dan studi pustaka. Analisis data dengan menggunakan analisis deskriptif. Hasil dari penelitian mengungkapkan kekuatan yang membentuk aktivitas di Fly-Over adalah karena adanya kesatuan aktor-ruang-waktu. Posisi aktor adalah sebagai unsur yang berperan utama dalam memaknai ruang (space) menjadi sebuah tempat (place), juga merupakan unsur yang menentukan dalam pembentukan sebuah peristiwa. Ruang sebagai unsur yang mewadahi berlangsungnya sebuah kegiatan atau peristiwa, sedangkan waktu adalah unsur yang "seolah-olah" mengatur, mengendalikan dan menentukan kapan peristiwa itu terjadi dan kapan peristiwa itu berhenti. Ketiga unsur aktorruang-waktu dalam sebuah peristiwa senantiasa bergerak, berubah, bergeser, berganti dan selalu menjadi satu kesatuan yang utuh.
\end{abstract}

Kata kunci : Ruang Publik; Fly-Over; Makassar

\begin{abstract}
Fly-over on Urip Sumoharjo KM.4 in Makassar is an overpass that built by the Makassar city government in order to solve the traffic jam that often occur becoming the increasing of traffic jam at a particular time because of the other activities that held by people of the city and which is the spatial problems of fly-over. The study aimed to reveal the forms of activities that held by its actors, and the strenght that formed the activities. The location of the Research is the fly-over on Urip Sumoharjo KM.4 in Makassar. The method of research conducted with qualitative methods. Data collection is taken by interviews, questionnaires, observations and literature study. Data analysis used descriptive analysis. The results of the study revealed the strength that formed the activity on The fly-over because of the unity of its actor, space and time. The position of the Actor is an element that played a main role in defining the space into a place, is also a decisive element in forming an event. Space is an element that accommodates an activitry or an event happened, while time is an element that seemed to regulate, control and determine when the eventshappened and when it stopped. The third element of the actor, space and time in an event constantly moved, changed, shifted and always be one whole unity.
\end{abstract}

Keywords : Public Space; Fly-Over; Makassar.

\footnotetext{
${ }^{1}$ Jurusan Arsitektur UIN Alauddin Makassar
} 


\section{PENDAHULUAN}

Perkembangan kota yang hanya didasari oleh aspek fisik, ekonomi dan politik tanpa memperhatikan aspek sosial dan budaya masyarakatnya terkadang menimbulkan fenomenafenomena baru dan menjadi masalah dalam perkotaan. Masyarakat yang menjadi aktor dalam kehidupan kota terkadang diabaikan kebutuhannya demi hasrat beberapa golongan penguasa semata. Hal ini menimbulkan chaos akan kebutuhan meruang didalam perkotaan.

Salah satu fenomena yang menarik untuk diamati dan menjadi masalah perkotaan adalah fenomena spasial penggunaan ruang publik di perkotaan. Penggunaan ruang publik kota seperti ruang terbuka hijau, ruang terbuka non-hijau dan jalanan yang didominasi oleh masyarakat sebagai aktor didalamnya, banyak menimbulkan masalah baru yang berbenturan dengan kebijakan yang dibuat oleh pemerintah mengenai fungsi dan tujuan dari ruang publik itu sendiri. Fungsi utama dari ruang publik, seperti jalan sebagai jalur sirkulasi kendaraan bermotor, koridor atau trotoar jalan untuk pejalan kaki seringkali digunakan oleh masyarakat (aktor) untuk aktivitas lain yang tidak sesusai dengan fungsi utamanya. Kehidupan kota sangat tergantung pada aktivitas komerisialnya (Fadhila SM, Nurul 2015). Permasalahan ini telah melanda hampir diseluruh kota di Indonesia khususnya kota-kota besar termasuk kota Makassar. (Lee 2006) mengemukakan bahwa fenomena dari kota yang tidak terlihat (the invisible cities) telah menunjukan adanya kecenderungan aktivitas dan kejadian spontan sebagai akibat dari penggunaan persepsi dan interpretasi terhadap ruang sebagai sebuah respon balik yang jujur atas lingkungan dan kebutuhan-kebutuhan manusia penggunanya. Melalui penggunaan yang tidak terduga terhadap ruang, "Arsitektur spontan" tercetus, dan timbul sebuah fenomena bermain yang sifatnya juga spontan.

Penelitian ini diawali dari ketertarikan penulis akan aktivitas yang terjadi di jalan Urip Sumoharjo yaitu di Fly-Over Urip Sumoharjo Makassar. Jalan yang merupakan ruang publik untuk jalur kendaraan bermotor digunakan oleh masyarakat kota untuk aktivitas lain seperti berdagang atau aktivitas ekonomi, nongkrong atau berkumpul, aktivitas istrahat atau tidur dan aktivitas politik bagi mahasiswa. Stephen Carr (1992) dalam (Zahnd 2006), bahwa manusia selalu memiliki keinginan untuk mendapatkan pemandangan dan pengalaman baru yang menyenangkan ketika mereka berada disuatu ruang publik dan hal ini merupakan salah satu kebutuhan yang mendasar dari sebuah ruang publik. Ruang tidak harus bersifat fisik dan nyata, ruang terdefenisikan oleh aktor yang menggunakannya (Soja 1996). Hal inilah yang dirasakan oleh aktor yang menggunakan Fly-Over sebagai ruang bagi aktivitas mereka. (Shirvani 1985), the theory of place, dimana space harus dapat dinyatakan sebagai place sehingga ruang menjadi bermakna bagi penggunanya.

Aktivitas-aktivitas ini seringkali menjadi masalah tersendiri bagi kota Makassar, Fly-Over yang dicanangkan oleh pemerintah kota sebagai jalur transportasi untuk memecah kemacetan yang sering terjadi malah menambah kemacetan di waktu-waktu tertentu.

Tujuan penelitian ini adalah untuk mengidentifikasi aktivitas-aktivitas yang menjadi fenomena spasial serta menjadi masalah di jalan ini dengan mengungkap kekuatan-kekuatan yang membentuk aktivitas pada fly-over.

\section{METODE}

Lokasi penelitian di wilayah Kota Makassar, yaitu di Fly-Over Urip Sumoharjo KM.4 Makassar. Jalan layang ini memiliki 2 bagian penting, yaitu bagian atas yang merupakan badan jalan layang itu sendiri, badan jalan yang digunakan sebagai jalur lalu lintas kendaraan dan bagian bawah atau area kolong dari jalan layang berupa area terbuka yang berfungsi sebagai taman dan pedestrian yang merupakan kesatuan yang tidak terpisahkan dari perencanaan dan keberadaan 
dari jalan layang (Fly-Over) Urip Sumoharjo. Waktu penelitian dilaksanakan mulai dari bulan Maret hingga bulan Agustus 2015.
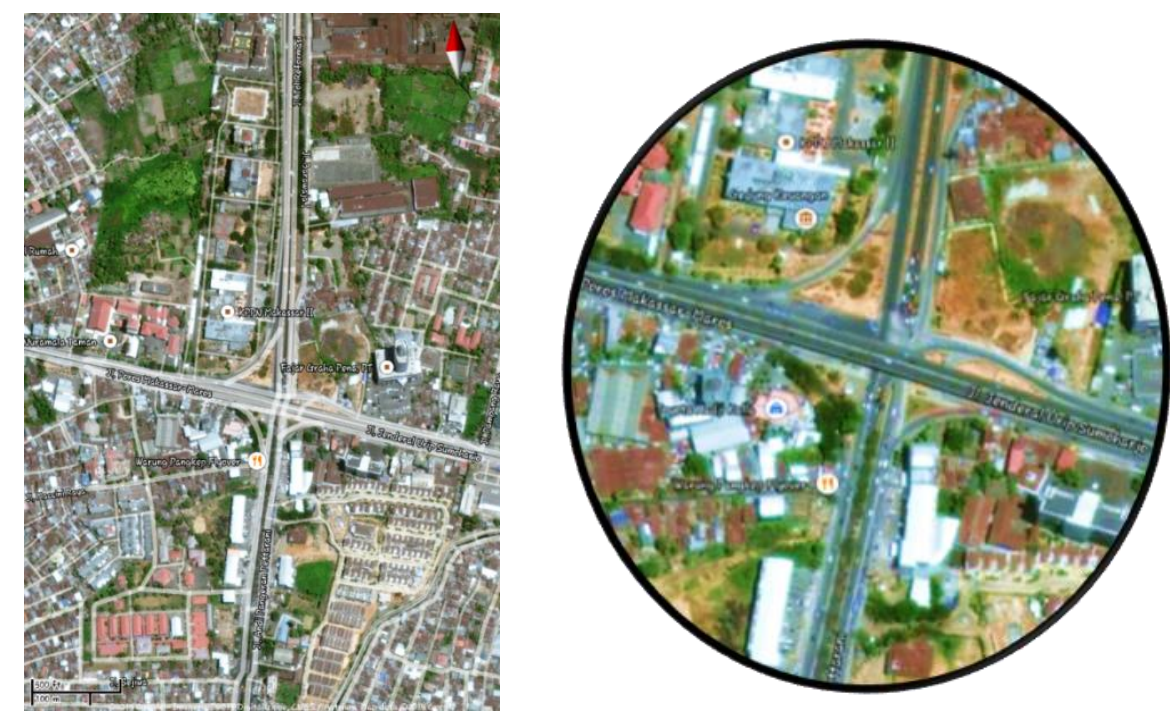

Gambar. 1: Fly-Over Jendral Urip Sumoharji KM 4 Makassar

Sumber: Olah Data, 2015

\section{Populasi dan Sampel}

Populasi dalam penelitian ini adalah aktor atau orang yang menggunakan Fly-Over sebagai tempat beraktivitas. Teknik penentuan sampel dengan cara random dari setiap aktivitas yang ada. Setiap aktivitas akan ditentukan jumlah sampelnya untuk mewakili populasi yang ada.

\section{Metode Pengumpulan Data}

Metode pengumpulan data dalam penelitian ini dilakukan dengan cara pengumpulan data primer yaitu dengan menyebar kuesioner, wawancara mendalam dan observasi yang bertujuan untuk mengidentifikasi jenis aktivitas, intensitas aktivitas dan proses terjadinya aktivitas di FlyOver, sedangkan data sekunder dikumpulkan melalui informasi berupa tulisan, koran, buku dan studi literatur yang mendukung (Patilima 2011).

\section{Analisis Data}

Dalam penelitian ini, data yang diperoleh dari peneliti akan dianalisis agar memperoleh data yang valid untuk disajikan sesuai dengan masalah yang dibahas. Penulis menggunakan tiga tahapan dalam melakukan analisis data. Reduksi data yaitu semua data di lapangan dianalisis sekaligus dirangkum, dipilih hal-hal yang pokok yang dianggap penting, dicari tema dan polanya sehingga tersusun secara sistematis dan mudah dipahami (Creswell 2010). Penyajian data, bertujuan untuk mengkomunikasikan hal-hal yang menarik dari masalah yang diteliti, penemuan yang diperoleh, penafsiran hasil, dan pengintegrasiannya dengan teori. Penarikan kesimpulan, pada tahap ini penulis membuat kesimpulan serta saran sebagai bagian akhir dari penelitian (Bungin 2003). 


\section{HASIL DAN PEMBAHASAN}

Hasil penelitian ini mengungkapkan yang menjadi kekuatan pembentuk aktivitas di FlyOver Urip Sumoharjo adalah karena adanya kesatuan aktor-ruang-waktu. Posisi aktor adalah sebagai unsur yang berperan utama dalam memaknai ruang (space) menjadi sebuah tempat (place) (Gambar 2), juga merupakan unsur yang menentukan dalam pembentukan sebuah peristiwa. Ruang sebagai unsur yang mewadahi berlangsungnya sebuah kegiatan atau peristiwa (Gambar 3), sedangkan waktu adalah unsur yang "seolah-olah" mengatur, mengendalikan dan menentukan kapan peristiwa itu terjadi dan kapan peristiwa itu berhenti (Gambar 4). Ketiga unsur aktor-ruang-waktu dalam sebuah peristiwa senantiasa bergerak, berubah, bergeser, berganti dan selalu menjadi satu kesatuan yang utuh. Ruang bisa berwujud fisik dengan sifat yang tetap namun aktor dapat memaknai ruang menjadi sesuatu yang lain, dapat mengubah bentuk dengan menambahkan sesuatu yang lain sehingga dapat mewujud dalam skala yang tidak terbatas. Dalam konteks waktu, ruang juga dapat meng-ada dan lenyap dengan sangat leluasa.

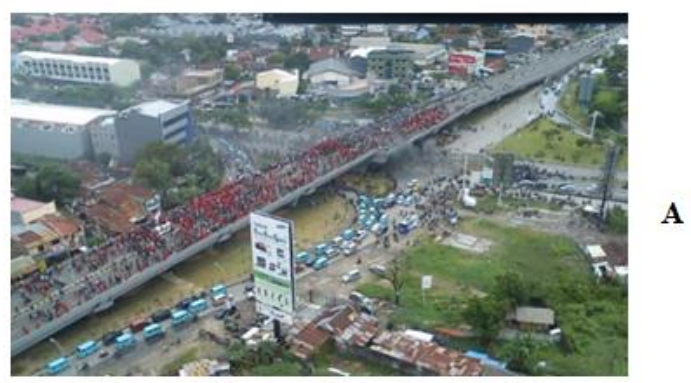

A

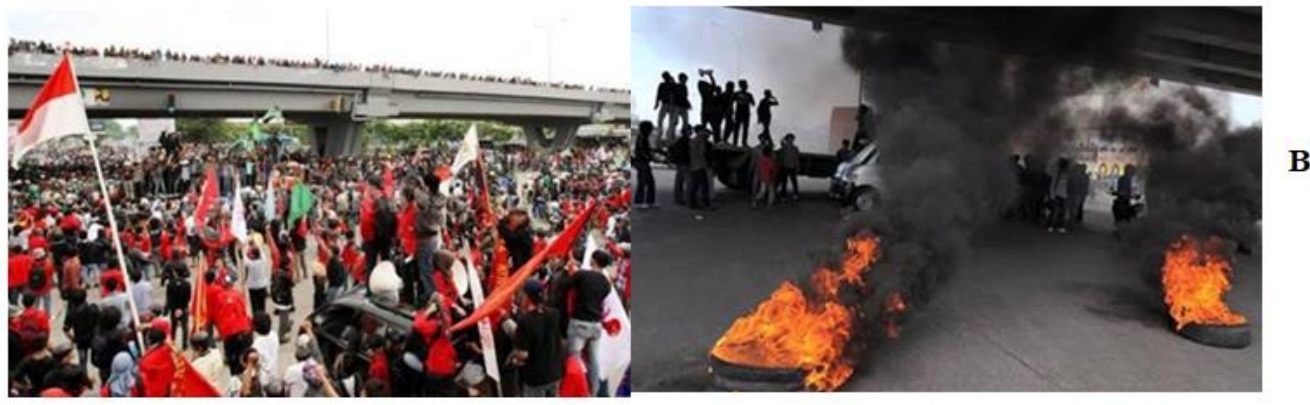

Gambar. 2: Aktivitas Demonstrasi Dimana Mahasiswa sebagai Aktor Mendefenisikan Ruang Sebagai Tempat Demonstrasi; (A) Proses Terbentuknya Aktivitas, (B) Suasana Demonstrasi di Fly-Over Urip Sumoharjo. Sumber: Hasil Analisis, Tahun 2015

Penelitian ini memperlihatkan bentuk-bentuk aktivitas yang terjadi pada Fly-Over Urip Sumoharjo Makassar. Pada awal mula beroperasinya jalan layang ini yaitu pada tahun 2009, kelompok yang pertama kali menggunakan jalan layang adalah mahasiswa yang menggelar orasi dan aksi mereka di atasnya. Seperti yang dikutip melalui Tribun Timur online, aktivitas mereka ini mendahului tahap uji coba jalan bagi kendaraan yang akan diselenggarakan oleh Otoritas Proyek Jalan Layang (Fly-Over) melalui Kepala Satuan Kerja Non Vertikal (SKNV) Departemen Pekerjaan Umum (PU) Makassar. 


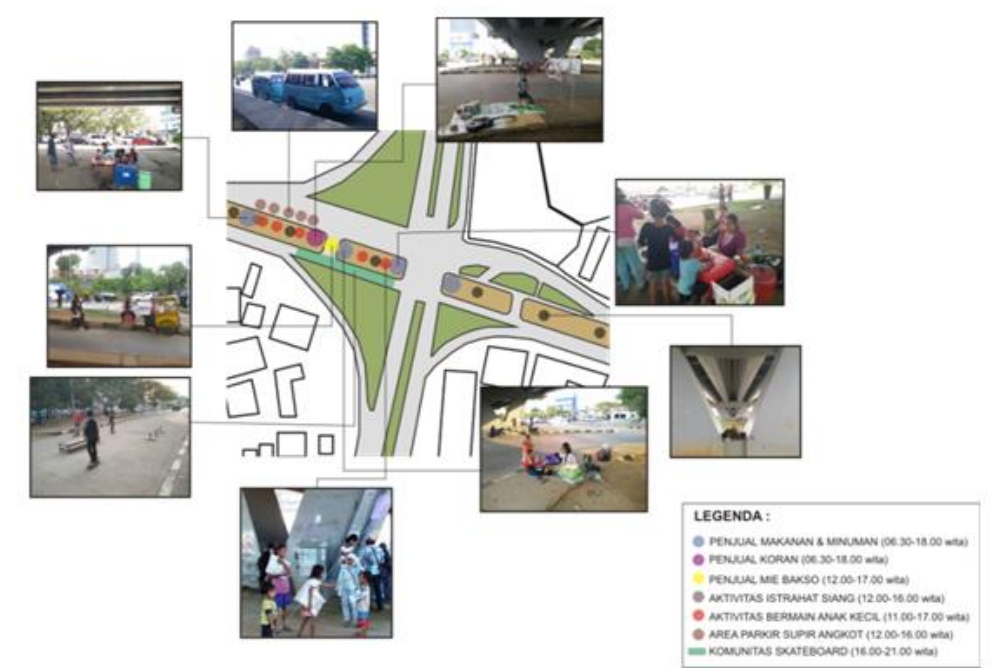

Gambar. 3: Pola Penyebaran Aktivitas di Kolong Fly-Over. Ruang di Kolong Fly-Over Merupakan Wadah untuk Bermacam Aktivitas.

Sumber: Hasil Analisis, Tahun 2015

Dari hasil wawancara oleh beberapa pihak terkait, baik dari aktivis mahasiswa dan dari pihak kepolisian, dapat diidentifikasi kecenderungan penggunaan ruang untuk aktivitas demonstrasi di area Fly-Over Urip Sumoharjo adalah dilihat dari segi letak jalan layang ini yang merupakan simpul pergerakan dari empat arah, yaitu dari Jalan A.P Pettarani menuju Jalan TOL Reformasi, dan dari Jalan Urip Sumoharjo menuju ke Jalan Perintis Kemerdekaan. Hal ini sangat memungkinkan aspirasi dari mahasiswa dapat tersampaikan oleh pengguna jalan di sekitarnya. Selain itu, jalan layang ini sangat berdekatan dengan kantor-kantor pemerintah seperti kantor DPRD Provinsi Sul-Sel, kantor Kejaksaan Tinggi Sul-Sel, kantor Pekerjaan Umum (PU), kantor BPK. Dilihat dari segi bentuk dan ruang; jalan layang ini merupakan area yang paling cocok digunakan sebagai "panggung" untuk orasi dan menyampaikan aspirasi. Area yang paling sering digunakan untuk aksi adalah area di bawah kolong jalan layang karena memiliki ruang yang cukup luas untuk menampung massa dan merupakan daerah teduh sehingga aksi bisa berjalan lancar tanpa harus menghiraukan panasnya matahari ataupun hujan. Apabila aksi demonstrasi dilakukan dengan skala yang lebih besar lagi, biasanya area di atas jalan layang ikut digunakan dengan cara memblokir jalan sehingga kendaraan harus menggunakan rute lama dengan memutar. Penggunaan ruas jalan layang (di bagian atas) memungkinkan aksi mereka menjadi pusat perhatian dari empat arah karena berada di ketinggian. Aksi-aksi politik yang dihasilkan dari ruang publik merupakan aksi-aksi yang kemudian diperhatikan oleh pihak pengambil keputusan (Hardiman 2010). Berasosiasi dengan lokasi beberapa kampus, ada beberapa kampus yang sering menggunakan ruang di jalan layang ini sebagai tempat untuk aksi demonstrasi, yaitu kampus UMI Makassar yang berlokasi di Jalan Perintis Kemerdekaan, Universitas 45 Makassar yang berlokasi di Jalan Perintis Kemerdekaan, Universitas UNM yang berlokasi di Jalan A.P Pettarani.

Aktivitas demonstrasi inilah yang memicu munculnya jenis aktivitas lain di area FlyOver. Keberadaan pedagang kecil yang menjual makanan dan minuman ringan semula hanya untuk mengakomodir kebutuhan dari aktivitas kalangan mahasiswa ini. Massa yang cukup banyak yang membutuhkan minuman dingin, makanan ringan ataupun rokok saat melakukan aksi adalah kesempatan atau peluang menguntungkan bagi pedagang kecil ini, mengingat intensitas aksi demo di tempat ini hampir terjadi 3-4 kali dalam sebulan. 


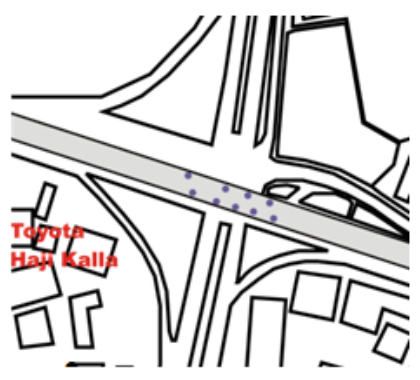

Intensitas aktor pada jam 18.00 wita

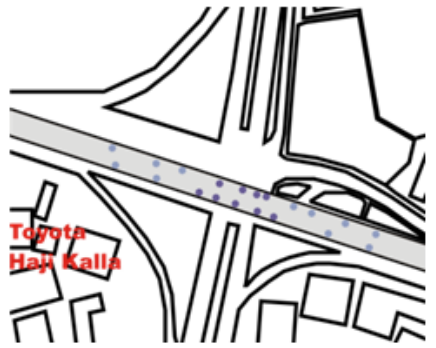

Intensitas aktor pada jam 22.00 wita

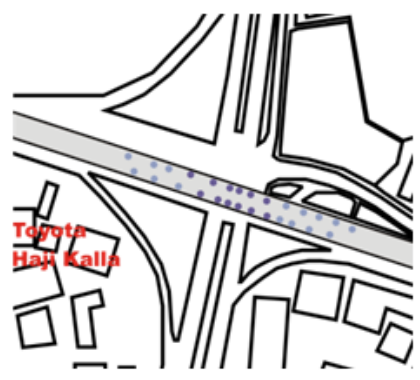

Intensitas aktor pada jam 20.00 wita

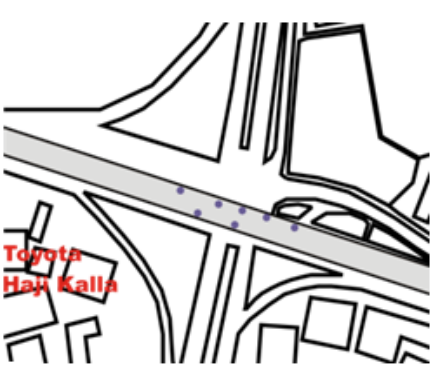

Intensitas aktor pada jam 23.00 wita

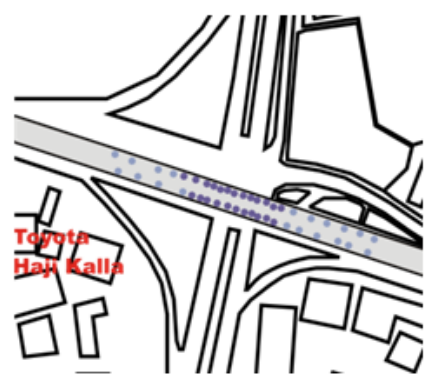

Intensitas aktor pada jam 21.00 wita

\section{LEGENDA : \\ - KECENDRUNGAN PENGGUNAAN RUANG KARENA PANORAMA KOTA} - KECENDRUNGAN PENGGUNAAN RUANG KARENA KERAMAIAN

Gambar. 4: Penggunaan Ruang Di Atas Jembatan Layang Untuk Aktivitas Duduk-Duduk Dan "Nongkrong” Pada Malam Hari Dimana Waktu Menentukan Berlangsungnya Aktivitas.

Sumber: Hasil Analisis, Tahun 2015

Dari hasil wawancara dengan pedagang ini, omset mereka juga meningkat dengan berdagang di area ini dibandingkan di tempat lain. Yang biasanya hanya mendapatkan pemasukan Rp. 20.000 - Rp. 30.000 tiap harinya, di tempat ini mereka mendapatkan rata-rata R p. 30.000 - Rp. 35.000 tiap harinya. Jalan merupakan ruang ekonomi dan politik suatu kota dimana menjadi tempat penduduk berkumpul dan bertukar informasi. Allan B. Jacobs (1985) dalam (Heryanto 2011) menyatakan jalan adalah untuk kegiatan ekonomi dimana masyarakat pedagang menggelar dagangannya, karena sifatnya yang menarik orang yang berlalulalang. Jalan adalah tempat dimana pemerintah mengawasi konflik antara kebijakan yang dikeluarkan dan pendapat dari masyarakat.
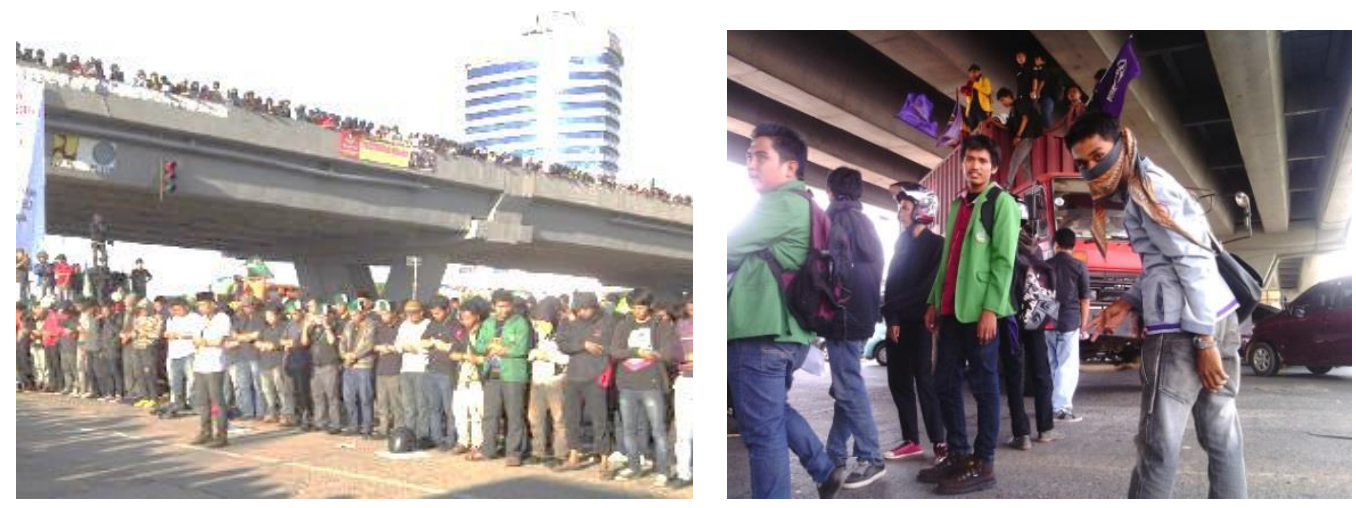

Gambar. 5: Demonstrasi. Salah Satu Aktivitas yang Sering Terjadi di Fly-Over Urip Sumoharjo yang Dilakukan oleh Aktivis Mahasiswa.

Sumber : Hasil Observasi, Tahun 2015 
Aktivitas para pedagang ini diikuti oleh kemunculan aktivitas serupa seperti penjual koran dan pedagang mie bakso gerobak yang juga mengambil tempat di area ini. Selain itu, dengan adanya aktivitas dari pedagang yang membuat warung kopi dadakan di bawah kolong Fly-Over mengundang aktivitas dari supir angkutan kota untuk singgah pada siang hari dengan tujuan untuk menikmati kopi, makan ataupun istrahat siang.

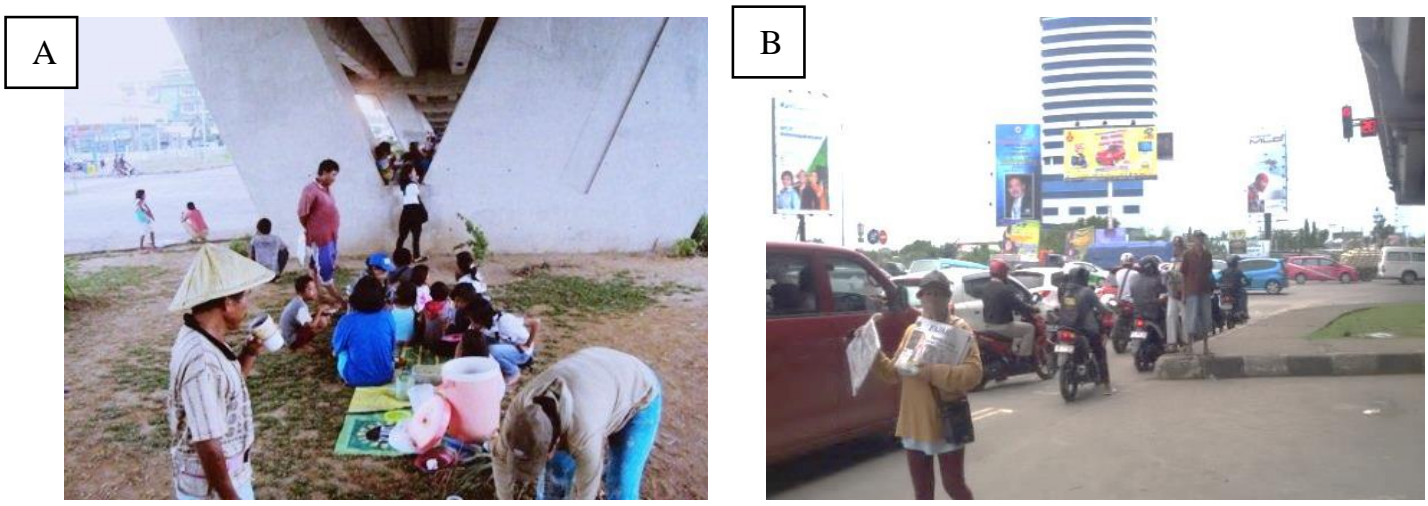

Gambar. 6: Pedagang Makanan dan Pengamen Jalanan Mulai Mengisi Kolong Fly-Over pada Pagi Hari (A), Penjual Koran Memulai Aktivitas Mereka pada Pagi Hari Dengan Memencar ke Jalan Sekitar Dekat Lampu Merah (B). Sumber : Hasil Observasi, Tahun 2015

Kurangnya perhatian dari Pemerintah Kota khususnya di area ini juga menjadi salah satu kekuatan yang membuat aktivitas-aktivitas ini bertahan hingga sekarang. Seperti aktivitas yang dilakukan oleh tunawisma yang saat ini menjadi penghuni tetap di kolong Fly-over, penguasaan ruang di tiang berbentuk "V" sebagai ruang istrahat (tempat untuk tidur) adalah salah satu bentuk penguasaan aktor terhadap ruang.Tunawisma yang menjadi aktor mendefenisikan ruang di kolom "V" sebagai ruang tidur mereka, ruang sebagai unsur yang mewadahi berlangsungnya kegiatan mereka (De Ven 1995).

Begitu juga halnya yang dilakukan oleh komunitas skateboard pada sore hari. Menguasai ruas jalan yang tidak dilalui oleh kendaraan di area kolong Fly-Over untuk aktivitas mereka dikarenakan tidak adanya peraturan yang melarang mereka untuk beraktivitas di area itu. Aktivitas komunitas skateboard ini telah ada sejak tahun 2011, yang awalnya aktivitas mereka diwadahi di lapangan Karebosi. Ruang yang dipilih adalah area jalan di bawah kolong Fly-Over yang tidak lagi dilalui oleh kendaraan bermotor. Jalan yang datar dan licin adalah syarat utama untuk aktivitas ini karena papan seluncur yang digunakan mutlak harus digunakan pada area datar dan licin. Selain karena di tempat ini tidak mendapatkan larangan untuk bermain, bagi komunitas ini juga menganggap area di jalan terbuka dapat memberikan pengalaman yang berbeda. Mereka berharap mendapat perhatian dari orang-orang yang berlalu-lalang di sekitar jalan Urip Sumoharjo baik dari pengendara bermotor maupun dari aktor lain. 

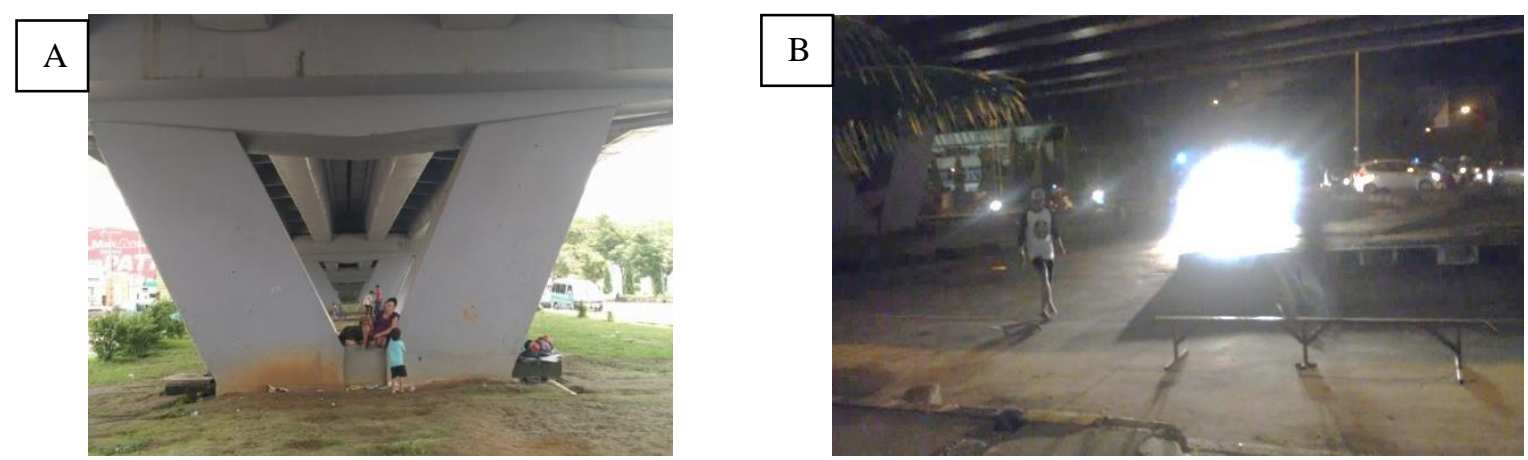

Gambar. 6. Aktivitas dari Tunawisma yang Menggunakan Ruang di Tengah Kolom Berbentuk "V" Sebagai Ruang Tidur Mereka (A). Aktivitas Komunitas Skateboard yang Terjadi pada Sore Hari di Kolong Fly-Over (B) Sumber : Hasil Observasi, Tahun 2015

Untuk aktivitas berkumpul dan nongkrong di malam hari oleh warga kota khususnya bagi anak muda Makassar, aktivitas ini hadir dari awal berdirinya jalan layang atau Fly-Over Urip Sumoharjo. Adapun alasan penggunaan ruang dari para aktor adalah karena ingin melihat panorama kota Makassar di sore dan malam hari; bagi warga kota yang ingin melihat pemandangan kota, sibuknya kendaraan yang terjadi di jalan dan gemerlap lampu kota di malam hari adalah kekuatan utama yang membentuk aktivitas ini. Khususnya bagi aktor yang sering melewati jalan layang ini setelah pulang kerja, singgah dan duduk menikmati pemandangan kota, lampu-lampu kota dapat membantu mereka meredam tingkat stres dan mengurangi kepenatan mereka setelah bekerja. Kekuatan ini pula yang membuat aktor semakin ramai dihari-hari menjelang akhir pekan. Alasan lain adalah karena ingin mencari keramaian; ributnya suara kendaraan, ramainya suasana jalan, ritme aktor yang datang dan pergi adalah salah satu kekuatan yang membuat sebagian orang betah duduk dan berkumpul di tempat ini. Khususnya di Kota Makassar, ruang publik kota baik yang terbuka maupun yang tertutup seperti mall dan cafe adalah tempat alternatif bagi masyarakat Kota Makassar untuk menghilangkan kejenuhan mereka. Khususnya yang memilih Fly-Over, mereka rata-rata adalah warga kota yang tinggal di sekitar FlyOver. Alasan terakhir adalah sekedar karena rasa penasaran, adanya aktivitas dari para aktor di jalan ini membuat sebagian aktor lain penasaran ada apa dan apa yang dilakukan orang kebanyakan di tepi jalan ini. Dengan kata lain, aktivitas aktor yang membentuk dan menjadi kekuatan dari kategori ini. Aktor dalam kategori ini sebenarnya tidak memiliki kebutuhan tertentu untuk singgah dan duduk di ruang ini. Tidak dapat merasakan sesuatu dari tempat ini selain rasa penasaran mereka sehingga tidak ada pula alasan untuk tinggal lebih lama di tempat ini. Mereka juga tidak memiliki rutinitas di tempat ini, mereka adalah orang yang pertama kali singgah dan tidak akan datang untuk kedua kalinya. 

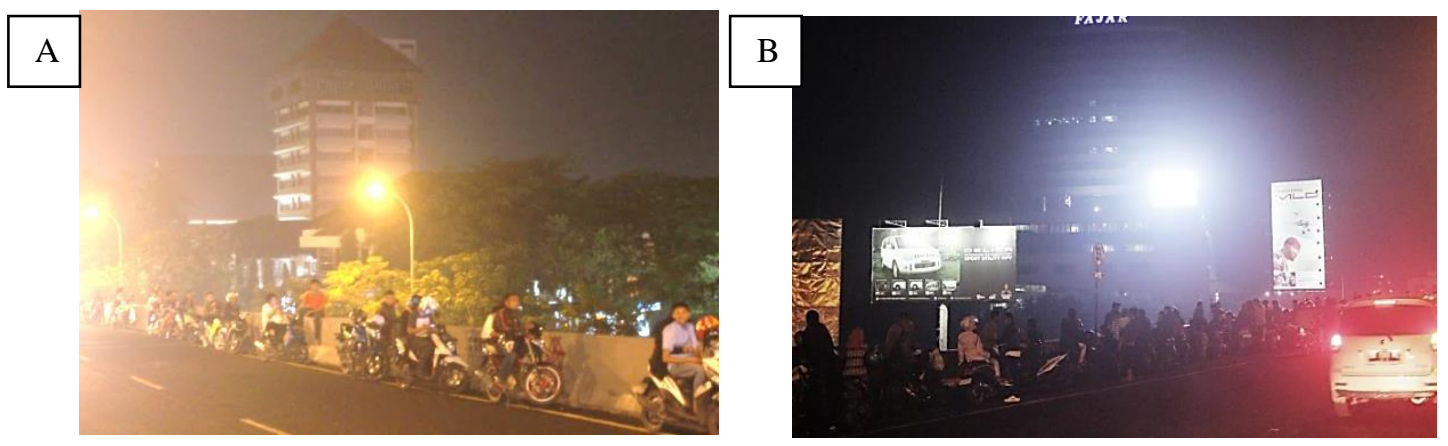

Gambar. 7: Ruas Jalan Fly-Over pada Malam Hari Digunakan oleh Aktor untuk Berkumpul dan DudukDuduk (A), Suasana Ramai Terlihat pada Waktu Weekend Aktivitas Berkumpul dan Duduk-Duduk di Fly-Over oleh Aktor (B).

Sumber : Hasil Observasi, Tahun 2015

Dari ketiga alasan penggunaan ruang jalan Fly-Over di atas, penulis menyimpulkan bahwa ada kebutuhan aktor akan pengalaman meruang yang tidak didapatkan dari tempat lain di Kota Makassar. Bukan hanya sekedar ingin menikmati pemandangan dan menikmati keramaian, tetapi juga karena ada sensasi lain atau pengalaman lain yang dirasakan oleh aktor mengingat ruang publik yang mereka pilih merupakan jalan yang ramai dengan kendaraan dan berada di ketinggian dari jalan di sekitarnya.

\section{KESIMPULAN}

Berdasarkan kecendrungan pengunaan ruang disimpulkan bahwa ruang dan urgensi letaknya merupakan kekuatan pembentuk aktivitas. Selain itu, ramainya kendaraan di jalan dalam hal ini adanya aktor lain juga merupakan kekuatan dalam pembentukan ruang. Secara garis besar dapat disimpulkan bahwa yang menjadi kekuatan pembentuk aktivitas di Fly-Over Urip Sumoharjo adalah karena adanya kesatuan aktor-ruang-waktu. Ketiga unsur aktor-ruang-waktu dalam sebuah peristiwa senantiasa bergerak, berubah, bergeser, berganti dan selalu menjadi satu kesatuan yang utuh. Ruang bisa berwujud fisik dengan sifat yang tetap namun aktor dapat memaknai ruang menjadi sesuatu yang lain, dapat mengubah bentuk dengan menambahkan sesuatu yang lain sehingga dapat mewujud dalam skala yang tidak terbatas. Dalam konteks waktu, ruang juga dapat meng-ada dan lenyap dengan sangat leluasa. Kasus fenomena spasial yang terjadi di Fly-Over Urip Sumoharjo KM.4 Makassar adalah bagian kecil dari masalah spasial yang terjadi di ruang publik kota Makassar. Dengan melihat kekuatan yang membentuk aktivitas, dibutuhkan kerangka pikir baru atau cara pandang baru bagi Pemerintah Kota Makassar dalam memahami dan menangani masalah kota Makassar khususnya masalah penggunaan ruang publik. Untuk wilayah Fly-Over Urip Sumoharjo KM.4 Makassar, diharapkan adanya perhatian khusus dari stake-holder baik dari segi pemeliharaan, penataan dan regulasi penggunaan ruang Fly-over. Penataan taman dan pedestrian di kolong Fly-Over yang baik dan dapat mengakomodasi kebutuhan ruang dari aktor, serta penataan jalan dan kontroling agar tidak terjadi kecelakaan dan kemacetan. 


\section{DAFTAR REFERENSI}

Bungin, B. 2003. Analisis Data Penelitian Kualitatif. Jakarta: Raja Grafindo Persada.

Creswell, J.W. 2010. Research Design: Pendekatan Kualitatif, Kuantitatif, Dan Mixed. Yogyakarta: Pustaka Pelajar.

Fadhila SM, Nurul, Wasilah. 2015. "Kawasan Pemukiman Veteran Makassar Penekanan Arsitektur Kolonial." Nature : National Academic Journal of Architecture 5 (2): 110-21.

Hardiman. 2010. Ruang Publik: Melacak "Partisipasi Demokratis" Dari Polis Sampai Cyberspace. Yogyakarta: Kanisius.

Heryanto. 2011. Roh Dan Citra Kota: Peran Perancangan Kota Sebagai Kebijakan Publik. Surabaya: Brilian Internasional.

Lee, Viray. 2006. Playing White. Singapore: JS Erwin.

Patilima, H. 2011. Metode Penelitian Kualitatif. Alfabeta.

Shirvani. 1985. Urban Design Process. New York: Van Nostrand Heinhold Company.

Soja. 1996. Third Space: Journeys to Los Angeles and Other Real-and-Imagined Places. Blackwell Publishers. Inc: Massacushetts.

Ven, C. Van De. 1995. Ruang Dalam Arsitektur. Jakarta: Gramedia Pustaka Utama.

Zahnd. 2006. Perancangan Kota Terpadu: Teori Perancangan Kota Dan Penerapannya.

Yogyakarta: Kanisius. 